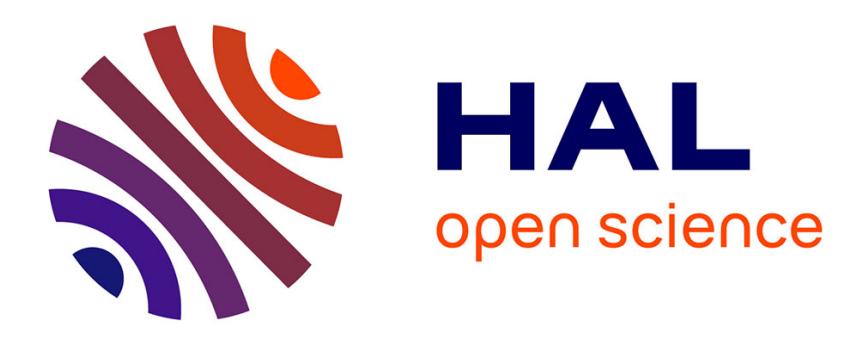

\title{
Modal Amplitude Stability Analysis and its application to brake squeal
}

\author{
S Nacivet, Jean-Jacques Sinou
}

\section{To cite this version:}

S Nacivet, Jean-Jacques Sinou. Modal Amplitude Stability Analysis and its application to brake squeal. Applied Acoustics, 2017, 116, pp.127 - 138. 10.1016/j.apacoust.2016.09.010 . hal-03257946

\section{HAL Id: hal-03257946 \\ https://hal.science/hal-03257946}

Submitted on 11 Jun 2021

HAL is a multi-disciplinary open access archive for the deposit and dissemination of scientific research documents, whether they are published or not. The documents may come from teaching and research institutions in France or abroad, or from public or private research centers.
L'archive ouverte pluridisciplinaire HAL, est destinée au dépôt et à la diffusion de documents scientifiques de niveau recherche, publiés ou non, émanant des établissements d'enseignement et de recherche français ou étrangers, des laboratoires publics ou privés. 


\title{
Modal Amplitude Stability Analysis and its application to brake squeal
}

\author{
S. Nacivet ${ }^{1, a}$ and J-.J. Sinou ${ }^{2,3, b}$ \\ 1 PSA Peugeot Citroën, Centre technique de La Garenne Colombes, \\ 18 rue des Fauvelles 92250 La Garenne Colombes, France \\ ${ }^{2}$ Laboratoire de Tribologie et Dynamique des Systèmes UMR CNRS 5513 \\ Ecole Centrale de Lyon, 36 avenue Guy de Collongue 69134 Ecully Cedex, France \\ 3 Institut Universitaire de France, 75005 Paris, France \\ asamuel.nacivet@mpsa.com, bjean-jacques.sinou@ec-lyon.fr
}

\begin{abstract}
In the present study, a new approach is proposed to predict the occurrence of squeal in brake systems. This strategy, called Modal Amplitude Stability Analysis (MASA), is based on the calculation of the first harmonic state-space system of nonlinear original equations using a specific linearization of the nonlinear contact forces at the frictional interfaces. An estimation of the occurrence and generation of increasing self-excited vibration is proposed on the basis of monitoring and the evolution of the real parts of the dynamic system considered as a function of modal amplitudes.

The application of the proposed MASA methodology to a real industrial brake system is presented. The occurrence of unstable modes and the generation of increasing self-excited vibrations strongly depends on the initial predefined modal amplitudes. The occurrence of new unstable modes (not predicted by classical stability analysis) can be detected. Therefore the MASA methodology appears to be a good compromise in terms of computing time and ease of implementation between the classical Complex Eigenvalue Analysis (CEA) and more complex nonlinear methods (such as the Generalized Constrained Harmonic Balance Method used to predict periodic and quasi-periodic motion).
\end{abstract}




\section{Introduction}

The problem of friction-induced vibration has been the subject of many investigations over recent decades. Overviews on friction-induced vibration can be found in [1 $[4]$. Several experimental and numerical investigations have been carried out for studying the significant impact of contact surface topography, the local contact pressure distribution or the frictional contact model [5 7]. Some researchers applied uncertainty analyses by conducting Monte Carlo simulations [8] or polynomial chaos expansions [9] for brake squeal propensity estimations. Butlin and Woodhouse [10] applied the 1st-order perturbation method to study the sensibility and uncertainty of friction-induced vibrations. Uncertainty quantification of squeal instability via kriging surrogate model of brake systems was also investigated to estimate the probability of brake squeal [11 13]. The modelling of the variability of brake lining surfaces was carried out by Renaud et al. [14. Numerical simulations in the past decade have been also focused on the prediction of unstable vibration modes by investigating the effects of damping [15 17] or multilayer viscoelastic insulators 18 on coalescences patterns. Recently, more research has been aimed at calculating the acoustic radiation of brake squeal using models of simplified brake systems with friction contact 19,20 . Despite all these studies, it is still difficult to predict the occurrence of squeal noise early enough to reduce development costs in the manufacturing process of brake systems. As a result, squeal is still responsible for a large number of nuisances in the field of automotive engineering. The problem of predicting squeal noise and understanding the mechanisms at the origin of squeal are a current challenge for the scientific community and the automotive industry.

In general, the numerical strategy for predicting squeal noise can be decomposed into two main parts: the complex eigenvalue analysis (CEA) and the transient and nonlinear analysis. The first concerns the stability analysis around nonlinear static sliding equilibrium points. The classical Complex Eigenvalue Analysis (CEA) is performed on the linearized system to predict the squeal propensity of the brake in a given frequency range. Although this first step is commonly used in industry, it only allows predicting the onset of instability around a given equilibrium point for a nonlinear system. Calculations of the transient and nonlinear vibrations are mostly performed by numerical integrations 21,23 . Recently, Iroz et al. 24 emphasized the potential of an elastic multibody approach to predict the amplitudes of the friction-induced vibrations and the contact forces at the disc-pad interfaces.

As previously explained in [25], more realistic results can be achieved via the nonlinear anal- 
ysis if the brake system model is sufficient. Sinou et al. [21,26] pointed out that CEA may lead to under- or over-estimation of unstable modes due to the contributions of the nonlinearities (such as nonlinear contact) and suggested both CEA and time domain analysis need to be considered in brake squeal analysis. Oberst and Lai [23] applied transient analysis to a finite element padon-disc brake model. They showed the CEA both over- and under-predicts instability. In [27], they also pointed out the nonlinear character of brake squeal and the potential of using nonlinear statistical analysis tools to analyse brake squeal. They also indicated that brake squeal can be treated as a chaotic phenomenon 28. While it is standard practice to use the complex eigenvalue analysis to predict unstable vibration modes in an industrial context, the transient nonlinear time domain analysis can become computationally so expensive that it is now considered impractical. Consequently, other methods for estimating approximated nonlinear dynamic steady-state solutions for autonomous systems subjected to single and multi-instabilities have been proposed and developed by Coudeyras et al. 29] to reduce automotive squeal noise. This strategy, known as the Generalized Constrained Harmonic Balance Method (GCHBM), allows predicting both periodic and quasi-periodic solutions and the associated unstable frequencies. Although this method has many advantages and, more specifically, predicts nonlinear signature squeal, we are obliged to admit that this approach requires many computational developments and its use in finite element models remains rare.

In this paper, we propose an approach to provide a simplified estimation of the occurrence of squeal for brake systems, by estimating not only the stability of the equilibrium point but also the emergence of unstable frequencies at the initial increase of divergence. This new strategy is based on an approximation of the evolution of an eigenvalue real part when the amplitudes of the initial nonlinear vibrations increase. The objective here is not to find and estimate the non-linear dynamic behavior but to provide additional analysis for the Complex Eigenvalue Analysis.

The paper is organized as follows. Firstly, the brake system under study, the general nonlinear equations of the numerical model and the classical stability analysis (based on a Complex Eigenvalue Analysis) of the complete brake system are presented. Next, the Modal Amplitude Stability Analysis (MASA) is defined using the first harmonic equations of the Harmonic Balance Method (HBM) and a new linearization for nonlinear forces. Finally, the results obtained by MASA are presented. 


\section{Automotive braking system and the formulation of the prob- lem}

\subsection{The finite element model under study}

In this study, we consider a finite element model of an industrial automotive brake system (see figure 1). The numerical model used in this paper was explained previously in detail in [36]. The latter study presented a numerical process based on modal reduction to minimize the size of a model through specific nonlinear modeling at the frictional interface to correctly predict both the nonlinear static equilibrium and the stability analysis of large finite element models.

In the present work, the nonlinear equation of the brake system can be written in the following form:

$$
\mathbf{M U}+\mathbf{C} \dot{\mathbf{U}}+\mathbf{K}_{\mathrm{nl}} \mathbf{U}+\mathbf{F}_{\mathrm{nl}}(\mathbf{U})=\mathbf{F}_{\mathrm{ext}}
$$

where $\mathbf{M}$ and $\mathbf{C}$ are the classical mass and damping matrices, respectively. $\mathbf{F}_{\mathrm{nl}}$ is related to the nonlinear forces occurring at the disc/pad interfaces. These nonlinear forces contain contributions from both the contact nonlinear forces and frictional forces at the pad/disc interface. A more detailed description of these nonlinear contributions will be given later. $\mathbf{F}_{\text {ext }}$ defines the piston pressure force (i.e. the vector of external forces) which acts on the pads entering into contact with the disc. $\mathbf{K}_{\mathrm{nl}}$ is the stiffness matrix due not only to the structural components of each component of the automotive brake system but also the three contact interfaces between the piston and the pad, the bracket and the pad and the caliper and the pad. This contribution is described by the following mathematical function:

$$
\mathbf{K}_{\mathrm{nl}} \mathbf{U}=\mathbf{K} \mathbf{U}+\mathbf{F}_{\text {piston } / \text { pad }}(\mathbf{U})+\mathbf{F}_{\text {bracket } / \text { pad }}(\mathbf{U})+\mathbf{F}_{\text {caliper } / \text { pad }}(\mathbf{U})
$$

where $\mathbf{K}$ is the classical stiffness matrix and vectors $\mathbf{F}_{\text {piston/pad }}(\mathbf{U}), \mathbf{F}_{\text {bracket/pad }}(\mathbf{U})$ and $\mathbf{F}_{\text {caliper/pad }}$ define the equivalent stiffness contributions for the interfaces of the two sub-systems in question. Two states are feasible for each of the three interfaces described previously: the possibility of linear contact or loss of contact for each interface. On the assumption of a contact state, not only normal forces but also friction forces due to the presence of friction at the interfaces are generated (i.e. the friction forces are deduced from the normal contact forces using the classical Coulomb law).

We recall that the role of damping remains an extremely important issue in the squeal problem. Recently, several new studies on the effect of damping on stability and on self-excited vibrations have been proposed. However, considering that investigating the role of damping 
is out of the scope of the present study, we refer to the following studies for those researchers interested 15, 17, 30. More specifically, the contribution of gyroscopic terms are neglected in the present work (see the following papers for more comments on the effects of gyroscopic terms [16 30,31]). Readers interested in the influence of velocity-dependent forces on the stability of non-conservative systems and the effects of nonlinearities or "following forces" can refer to O'Reilly et al. 32 and Kirillov and Seyranian [33 and Hermann and his colleagues 34,35.

As previously explained in [36, an implicit reduction at the frictional interface by generating an assembly of Super-Elements (SE) is proposed. This strategy was developed previously to define an original reduced contact interface at the disc/pad interface with a reduced number of nodes on both sides of the pad and disc that can be used later for condensation and node to node contact (for more details and a complete description of the Super-Element creation and Super-Element assembly, please refer to [36]). Furthermore, a classical Craig and Bampton reduction [29] is computed while the reduced number of nodes used in the disc/pad contact interface are kept as reduction nodes. Therefore the generation of nonlinear contact forces at the disc/pad interface contacts can be considered in our finite element model.

Considering the experimental data [29], we assume that the nonlinearities at the friction interface between the pad and the disc are both the cubic nonlinear terms and the possible loss of contact between the disc and the pad. The formulation can be summarized as follows for each reduced contact node:

$$
\mathbf{F}_{\text {contact,disc } / \text { pad }}= \begin{cases}k_{\mathrm{l}}\left(\mathbf{U}_{\mathrm{i}}-\mathbf{U}_{\mathrm{j}}\right)+k_{\mathrm{nl}}\left(\mathbf{U}_{\mathrm{i}}-\mathbf{U}_{\mathrm{j}}\right)^{3} & \text { if } \mathbf{U}_{\mathrm{i}}-\mathbf{U}_{\mathrm{j}}>\mathbf{0} \\ \mathbf{0} & \text { otherwise }\end{cases}
$$

where $\mathbf{U}_{\mathrm{i}}$ and $\mathbf{U}_{\mathrm{j}}$ are, respectively, the displacements of the coincident nodes $\mathrm{i}$ and $\mathrm{j}$ from the master and slave sides of the contact, respectively. $k_{\mathrm{l}}$ and $k_{\mathrm{nl}}$ are the linear and the non-linear stiffnesses, respectively. As explained previously in [29,36], a velocity field corresponding to the disc rotation is imposed on the disc surface. Therefore the friction forces at the pad/disc interface are deduced from the normal contact forces (previously defined in Equation 3) using a simplified Coulomb law with a constant friction coefficient.

[Fig. 1 about here.] 


\subsection{Stability analysis at nonlinear static equilibrium}

Firstly, the nonlinear static equilibrium point $\mathbf{U}_{\mathrm{s}}$ of the nonlinear equation of the brake system 1 has to be calculated. $\mathbf{U}_{\mathrm{s}}$ is obtained by solving the following relation:

$$
\mathbf{K}_{\mathrm{nl}, \mathbf{U}_{\mathrm{s}}} \mathbf{U}_{\mathrm{s}}+\mathbf{F}_{\mathrm{nl}}\left(\mathbf{U}_{\mathrm{s}}\right)=\mathbf{F}_{\mathrm{ext}}
$$

where $\mathbf{K}_{\mathrm{nl}, \mathbf{U}_{\mathrm{s}}}$ corresponds to the linearized stiffness matrix at the vicinity of the nonlinear static equilibrium. It can be noted that this contribution contains both the classical stiffness of the structural components of each component of the brake system and the linearized stiffness contributions with respect to the possibility of contact or no-contact for the three contact interfaces between the piston and the pad, the bracket and the pad and the caliper and the pad. Therefore, as previously explained in [36], all these contacts (except for the disc/pads interfaces) are linearized as a constant value in the stiffness matrix $\mathbf{K}_{\mathrm{nl}, \mathbf{U}_{\mathrm{s}}}$. Then, $\mathbf{F}_{\mathrm{nl}}\left(\mathbf{U}_{\mathrm{s}}\right)$ corresponds to the generation of the nonlinear contact and friction forces at the disc/pad interfaces around the static equilibrium.

By substituting a small perturbation $\Delta \mathbf{U}$ around the static equilibrium $\mathbf{U}_{\mathrm{s}}$ in Equation 1 and by considering the previous relation of Equation 4 , we obtain:

$$
\mathbf{M} \Delta \ddot{\mathbf{U}}+\mathbf{C} \Delta \dot{\mathbf{U}}+\mathbf{K}_{\mathrm{nl}, \mathbf{U}_{\mathrm{s}}} \Delta \mathbf{U}+\mathbf{F}_{\mathrm{nl}}\left(\mathbf{U}_{\mathrm{s}}+\Delta \mathbf{U}\right)-\mathbf{F}_{\mathrm{nl}}\left(\mathbf{U}_{\mathrm{s}}\right)=\mathbf{0}
$$

where $\mathbf{K}_{\mathrm{nl}, \mathbf{U}_{\mathrm{s}}}$ defines the linearized stiffness matrix in the vicinity of the static equilibrium $\mathbf{U}_{\mathrm{s}}$.

As proposed by Fazio et al. [36], the nonlinear law used in Matlab is tuned according to the Abaqus results (contact forces and gaps) for each contact element (see Equation 3). It is important to note that this tuning procedure is dependent on the friction coefficient $\mu$ and external loads as they affect the static equilibrium state.

Then, the system is linearized around the nonlinear static equilibrium and the associated eigenvalue problem is solved by resolving the following equation:

$$
\left(\lambda^{2} \mathbf{M}+\lambda \mathbf{C}+\left(\mathbf{K}_{\mathrm{nl}, \mathbf{U}_{\mathrm{s}}}+\mathbf{J}_{\mathrm{nl}}\right)\right) \phi=\mathbf{0}
$$

where $\mathbf{J}_{\mathrm{nl}}$ corresponds to the nonlinear force linearization of $\mathbf{F}_{\mathrm{nl}}$ around the nonlinear static equilibrium point $\mathbf{U}_{\mathrm{s}}$. The complex eigenvalues can then be written as follows: $\lambda_{i}=a_{i}+$ $\mathrm{j} \omega_{i}$ where $\mathrm{j}$ defines the imaginary unit. $\omega_{i}$ represents the angular frequency of the associated eigenmode $\phi_{i}$. If the real part $a_{i}$ of an eigenvalue is positive, the corresponding eigenmode is considered unstable and can thus generate brake squeal. The results on the stability analysis for the undamped industrial representative brake system under study are given in Figure 2 
the evolutions for the six main instabilities (for both real parts and frequencies) at $1.98 \mathrm{kHz}$, $3.69 \mathrm{kHz}, 3.85 \mathrm{kHz}, 4.72 \mathrm{kHz}, 4.94 \mathrm{kHz}$ and $5.34 \mathrm{kHz}$ on the $0-6 \mathrm{kHz}$ range are shown by increasing the friction coefficient $\mu$ of the disc/pad interfaces. For the sake of clarity, these results indicate one of the main contributions of the previous study [36]: it illustrates that it is possible to drastically reduce the number of contact nodes at the frictional disc/pad interfaces while being able to estimate the stability of the brake system. In the present study, the reduced models with 104 and 212 contact elements at the disc/pad frictional interface (called RM104 and RM212 respectively) are in good agreement with the Abaqus reference for which all the contact nodes are preserved (see Figures 2). Moreover, the results of the damped reduced finite element model (called RM212-damping) that will be used in the next sections are shown in Figures 2).

[Fig. 2 about here.]

\section{Modal Amplitude Stability Analysis (MASA) methodology}

In this section, the approach proposed to estimate the occurrence and triggering of the initial increase of self-excited vibration under predefined amplitudes of one unstable mode is presented. First, a new linearization for the first harmonic approximation of the contact forces using the relative displacements in the contact elements will be introduced. Then, the complex modal shape will be defined using the first harmonic displacements. Finally, the Modal Amplitude Stability Analysis (MASA) methodology will be developed. We recall that the objective of the methodology proposed here is not to predict the self-excited vibration of the brake system but to provide an additional analysis for the Complex Eigenvalues Analysis. These additional results are based on the prediction of the onset of unstable modes generated at the initiation of squeal instability.

\subsection{First harmonic state-space system using a new linearization of contact forces}

Considering the previous expression 6, Equation 5 can be rewritten in the following form:

$$
\mathbf{M} \Delta \ddot{\mathbf{U}}+\mathbf{C} \Delta \dot{\mathbf{U}}+\left(\mathbf{K}_{\mathrm{nl}, \mathbf{U}_{\mathrm{s}}}+\mathbf{J}_{\mathrm{nl}}\right) \Delta \mathbf{U}+\boldsymbol{\Omega}=\mathbf{0}
$$

where

$$
\boldsymbol{\Omega}=\mathbf{F}_{\mathrm{nl}}\left(\mathbf{U}_{\mathrm{s}}+\Delta \mathbf{U}\right)-\mathbf{F}_{\mathrm{nl}}\left(\mathbf{U}_{\mathrm{s}}\right)-\mathbf{J}_{\mathrm{nl}} \Delta \mathbf{U}
$$

Then, if $\boldsymbol{\Omega}=\mathbf{0}$, the associated eigenvalue problem corresponds to Equation 6 . 
For the sake of clarity, the reason for separating the terms of the previous equation of motion 7 in this way is to ensure continuity during the numerical calculation of the MASA methodology for $\Delta \mathbf{U}=\mathbf{0}$ (which implies $\boldsymbol{\Omega}=\mathbf{0}$ for Equation 8). Regarding the formulation proposed and the separation of the terms for the equation of motion 7 , the stability analysis for $\Delta \mathbf{U}=\mathbf{0}$ refers to Equation 6

The nonlinear solution of Equation 7 can be assumed to be a truncated Fourier series leading to an approximation of the nonlinear solution $\Delta \mathbf{U}(\mathbf{t})$ :

$$
\Delta \mathbf{U}(t)=\sum_{k=\mathbf{0}}^{\mathbf{N}_{\mathbf{h}}} \Delta \mathbf{U}_{k}(t)=\sum_{k=\mathbf{0}}^{\mathbf{N}_{\mathbf{h}}} \Delta \mathbf{U}_{k}^{\mathbf{C}} \cos (k \omega t)+\sum_{k=\mathbf{1}}^{\mathbf{N}_{\mathbf{h}}} \Delta \mathbf{U}_{k}^{\mathbf{S}} \sin (k \omega t)
$$

$\Delta \mathbf{U}_{k}(t)$ is the $k^{t h}$ harmonic in the time domain with $\Delta \mathbf{U}_{k}^{\mathbf{C}}$ and $\Delta \mathbf{U}_{k}^{\mathbf{S}}$ the associated vectors of Fourier coefficients. $\omega$ the final angular frequency of the nonlinear limit cycles.

Then, the nonlinear forces $\boldsymbol{\Omega}(t)$ can also be assumed to be a truncated Fourier series:

$$
\boldsymbol{\Omega}(t)=\sum_{k=\mathbf{0}}^{\mathbf{N}_{\mathbf{h}}} \boldsymbol{\Omega}_{k}(t)=\sum_{k=\mathbf{0}}^{\mathbf{N}_{\mathbf{h}}} \boldsymbol{\Omega}_{k}^{\mathbf{C}} \cos (k \omega t)+\sum_{k=\mathbf{1}}^{\mathbf{N}_{\mathbf{h}}} \boldsymbol{\Omega}_{k}^{\mathbf{S}} \sin (k \omega t)
$$

It is noteworthy that the vectors of Fourier coefficients $\boldsymbol{\Omega}_{k}^{\mathrm{C}}$ and $\boldsymbol{\Omega}_{k}^{\mathrm{S}}$ can be calculated by applying an Alternate Frequency/Time domain method (AFT-method) via the evaluation of $\boldsymbol{\Omega}(t)$ in the time domain (see [29] for more details).

By carrying over Equations 9 and 10 in Equation 7 and extracting the first harmonic component, we obtain:

$$
\mathbf{M} \Delta \ddot{\mathbf{U}}_{1}+\mathbf{C} \Delta \dot{\mathbf{U}}_{1}+\left(\mathbf{K}_{\mathrm{nl}, \mathbf{U}_{\mathrm{s}}}+\mathbf{J}_{\mathrm{nl}}\right) \Delta \mathbf{U}_{1}+\mathbf{\Omega}_{1}=\mathbf{0}
$$

where

$$
\begin{gathered}
\Delta \mathbf{U}_{1}=\Delta \mathbf{U}_{1}^{\mathbf{C}} \cos (\omega t)+\Delta \mathbf{U}_{1}^{\mathbf{S}} \sin (\omega t) \\
\boldsymbol{\Omega}_{1}=\boldsymbol{\Omega}_{1}^{\mathbf{C}} \cos (\omega t)+\boldsymbol{\Omega}_{1}^{\mathbf{S}} \sin (\omega t)
\end{gathered}
$$

Then, we propose to linearize $\boldsymbol{\Omega}_{1}$ such that:

$$
\boldsymbol{\Omega}_{1}=\mathbf{K}_{1} \Delta \mathbf{U}_{1}+\mathbf{C}_{1} \Delta \dot{\mathbf{U}}_{1}
$$

This previous form and more specifically the associated hysteretic damping allows taking into account the phase between the load component $\boldsymbol{\Omega}_{1}$ and the displacement component $\mathbf{U}_{1}$. Moreover, it can be observed that the coefficients of $\mathbf{K}_{1}$ and $\mathbf{C}_{1}$ can be evaluated for each contact element independently. For a given contact element, we can define the normal relative displacement as:

$$
\delta^{\mathrm{n}}(t)=\delta_{\mathrm{c}} \cos (\omega t)+\delta_{\mathrm{s}} \sin (\omega t)
$$


and, the effort between two degree-of-freedom according to a direction ${ }^{\mathrm{d}}$ which can be tangential or normal as in:

$$
\boldsymbol{\Omega}_{1}^{\mathrm{d}}(t)=\tau_{\mathrm{c}} \cos (\omega t)+\tau_{\mathrm{s}} \sin (\omega t)
$$

Then, for each direction ${ }^{\mathrm{d}}$, to check the following equation:

$$
\boldsymbol{\Omega}_{1}^{\mathrm{d}}(t)=\mathbf{k}^{\mathrm{d}, \mathrm{n}} \delta^{\mathrm{n}}(t)+\mathbf{c}^{\mathrm{d}, \mathrm{n}} \dot{\delta}^{\mathrm{n}}(t)
$$

we can define $\mathbf{k}^{\mathrm{d}, \mathrm{n}}$ and $\mathbf{c}^{\mathrm{d}, \mathrm{n}}$ such as:

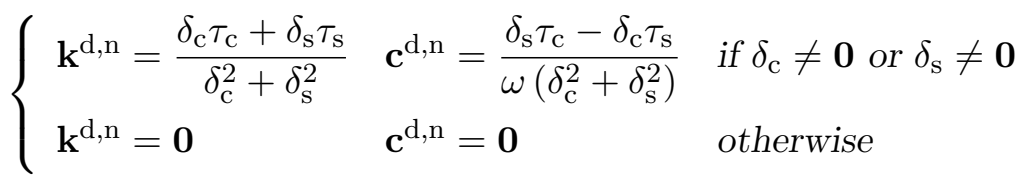

Using Equation 14 in Equation 11, the system can easily be rewritten in a state-space (i.e. $\left.\mathbf{Y}_{1}=\left(\begin{array}{ll}\Delta \mathbf{U}_{1} & \boldsymbol{\Delta} \dot{\mathbf{U}}_{1}\end{array}\right)^{T}\right)$ such as:

$$
\dot{\mathbf{Y}}_{1}=\mathbf{A} \mathbf{Y}_{1}
$$

where

$$
\mathbf{A}=\left[\begin{array}{cc}
\mathbf{0} & \mathbf{I} \\
-\mathbf{M}^{-\mathbf{1}}\left(\mathbf{K}_{\mathrm{nl}, \mathbf{U}_{\mathrm{s}}}+\mathbf{J}_{\mathrm{nl}}+\mathbf{K}_{1}\right) & -\mathbf{M}^{-\mathbf{1}}\left(\mathbf{C}+\mathbf{C}_{1}\right)
\end{array}\right]
$$

Matrix A can be used for a stability analysis including modal dynamics by retaining only the first harmonic component, which makes sense since the first harmonic is directly linked to the unstable mode (i.e. the instability frequency).

\subsection{Complex modal shape using first harmonic displacements and MASA methodology}

Equation 12 can be rewritten for the $i^{\text {th }}$ eigenvalue such as:

$$
\left\{\begin{array}{c}
\Delta \mathbf{U}_{1}=\mathbf{X}_{1} \mathbf{e}^{\lambda_{i} t}+\overline{\mathbf{X}}_{1} \mathbf{e}^{\bar{\lambda}_{i} t} \\
\Re\left(\lambda_{i}\right)=\mathbf{0}
\end{array}\right.
$$

where $\mathbf{X}_{1}=\left(\Delta \mathbf{U}_{1}^{\mathrm{c}}-\mathrm{j} \Delta \mathbf{U}_{1}^{\mathrm{s}}\right) / \mathbf{2}$. Here, we note that this first harmonic solution naturally introduces the stability condition given by $\Re\left(\lambda_{i}\right)=\mathbf{0}$ (see 29 for more details). If we have $\boldsymbol{\Delta} \mathbf{U}_{1} \neq \mathbf{0}$ ( $\boldsymbol{\Delta} \mathbf{U}_{1}$ being a known quantity) for an unstable mode (i.e. with the associated eigenvalue $\lambda_{i}$ ), $\lambda_{i}$ can be extracted directly from the matrix $\mathbf{A}_{i}$ by considering the following form:

$$
\lambda_{i}=\psi_{i}^{T} \mathbf{A}_{i} \psi_{i}
$$

where

$$
\psi_{i}=\frac{1}{\eta}\left(\begin{array}{c}
\mathbf{X}_{1} \\
j \omega_{i} \mathbf{X}_{1}
\end{array}\right)
$$


and

$$
\eta=\left\|\begin{array}{c}
\mathbf{X}_{1} \\
\mathrm{j} \omega_{i} \mathrm{X}_{1}
\end{array}\right\|
$$

Finally, the global strategy of the Modal Amplitude Stability Analysis method is based on a sweep according to the modal amplitude $p_{i}^{m}$, assuming that $\psi_{i}^{m}=\psi_{i}^{\mathbf{0}}$ and $\omega_{i}^{m}=\omega_{i}^{\mathbf{0}}$ are independent of the modal amplitude. $m$ refers to the sweep index. These assumptions are valid at very low amplitudes (i.e. we try to assess the evolution of instabilities in the first microimpacts by assuming that mode shapes do not change too much). For each value of $p_{i}^{m}, \mathbf{X}_{1}^{m}$ can be approximated using Equation 23 such as:

$$
\left(\begin{array}{c}
\mathbf{X}_{1}^{m} \\
\mathrm{j} \omega_{i}^{0} \mathbf{X}_{1}^{m}
\end{array}\right)=p_{i}^{m} \psi_{i}^{\mathbf{0}}
$$

Since $\psi_{i}^{m}$ is not updated according to the modal amplitude, $\lambda_{i}^{m}$ is not deduced from the previous Equation 22 but extracted from a Complex Eigenvalue Analysis performed on $\mathbf{A}_{i}^{m}$ (see Equation 20 .

[Fig. 3 about here.]

\section{Results}

In this section, we consider the reduced damped model RM212-damped in the $0-6 \mathrm{kHz}$ range due to the performance of the RM212 model compared to the reference model. As explained previously in the work of Fazio et al. 36 superelements are generated for each step of the unfolding parameter $\mu$ (i.e. from $\mu=0.1$ to $\mu=0.9$ with $\Delta \mu=0.1$ ) due to the fact that each reduced model depends on the value of the friction coefficient $\mu$.

The numerical approach is defined as follows: for each value of the unfolding parameter $\mu$, instabilities on the frequency range of interest (i.e. $0-6 \mathrm{kHz}$ ) are detected by using CEA (see the previous subsection 2.2 for more details). Then, for each instability, the modal amplitudes of the nonlinear system are evaluated independently using the MASA methodology by performing an incremental modal amplitude sweep (with a step $\Delta p$ ) for a chosen unstable mode. For a given value of the unfolding parameter $\mu$, all the eigenvalues real parts of the matrix $\mathbf{A}$ (see Equation 20 are calculated. If a real part is higher than zero, it corresponds to the increase of the unstable modes for a given initial modal amplitude.

In the following, the results will be presented for the sixth instabilities in the $0-6 \mathrm{kHz}$ range as indicated previously in Section 2.2 (at $1.98 \mathrm{kHz}, 3.69 \mathrm{kHz}, 3.85 \mathrm{kHz}, 4.72 \mathrm{kHz}, 4.94 \mathrm{kHz}$ and 
$5.34 \mathrm{kHz})$. First, the three main instabilities at $1.98 \mathrm{kHz}, 3.85 \mathrm{kHz}$ and $4.72 \mathrm{kHz}$ will be discussed in detail. Then, the results for the three other instabilities at $3.69 \mathrm{kHz}, 4.94 \mathrm{kHz}$ and $5.34 \mathrm{kHz}$ will be given.

First, Figures 4 show the evolution of the real parts of the dynamic system versus different initial modal amplitudes of the first instability (around $1.98 \mathrm{kHz}$ as seen in the previous section) and various frictional coefficients (from $\mu=0.6$ to $\mu=0.9$ with a step of $\Delta \mu=0.1$ ). It can be seen that the occurrence and generation of increasing self-excited vibrations (i.e. evolution of the real parts) can be different depending on the amplitude of the unstable mode (i.e. modal amplitude) for a given friction coefficient value. Several unstable modes can occur even if the initial conditions take into account only the amplitudes for the first unstable mode. For example, five unstable modes are generated in some configurations: see Figure 4(b) for $\mu=0.7$ and a modal amplitude between 10 and 210 (with five unstable modes at $2 \mathrm{kHz}, 3.85 \mathrm{kHz}, 4.7 \mathrm{kHz}$, $4.9 \mathrm{kHz}$ and $5.4 \mathrm{kHz}$ ) and Figure $4(\mathrm{~d})$ for $\mu=0.9$ and a modal amplitude between 0 and 300 (with five unstable modes at $2 \mathrm{kHz}, 3.7 \mathrm{kHz}, 3.85 \mathrm{kHz}, 4.7 \mathrm{kHz}$ and $5.4 \mathrm{kHz})$. Also, new unstable modes which were not predicted with the classical stability analysis for a specific value of the friction coefficient may appear. For example, in the case of $\mu=0.7$ (see Figure 4(b)), one unstable mode at $5.3 \mathrm{kHz}$ appears when the modal amplitude is between $[10-200]$. Similarly, instability at $4.9 \mathrm{kHz}$ appears for $\mu=0.8$ and $\mu=0.9$ while the classical stability analysis indicates that there is no unstable mode around this frequency for the friction coefficients considered. It is interesting to note, however, that the unstable modes that emerge at $4.9 \mathrm{kHz}$ and $5.3 \mathrm{kHz}$ were predicted by CEA (see Figures $2(\mathrm{e}-\mathrm{k})$ and (f-l)), but not for the same friction coefficient values. This illustrates the fact that the appearance of new unstable modes can be observed due to the evolution of the stability of an unstable solution. The evolution of the frequency of unstable modes as a function of the evolution of the modal amplitude can also be seen. This is particularly evident for the unstable mode around $4.7-5 \mathrm{kHz}$.

Figures 5 and 6 show results for the two instabilities at $3.85 \mathrm{kHz}$ and $4.72 \mathrm{kHz}$ as initial contributors for the modal amplitudes. Once again, it can be seen that the occurrence and generation of unstable vibrations depend on the initial modal amplitudes. More or less unstable modes can appear due to the evolution of both the value of the friction coefficient and the modal amplitudes. We can also conclude that the choice of the unstable mode used to initiate unstable amplitudes drastically influences the occurrence and evolution of all the unstable modes (compare Figures 4,5 and 6 for a selected friction coefficient value). For this specific case, a new unstable mode (at $5.7 \mathrm{kHz}$ ) that has never been predicted by CEA is present (see Figures 
6(b-f). This new contribution appears only for significant modal amplitudes. Some unstable modes can be seen to disappear when the modal amplitudes of the unstable modes chosen increase (see, for example, the unstable frequencies at $3.8 \mathrm{kHz}$ and $4.7 \mathrm{kHz}$ in Figures 5 (a-b); $5.2 \mathrm{kHz}$ and $5.6 \mathrm{kHz}$ in Figures $5(\mathrm{c}-\mathrm{d}) ; 4.7 \mathrm{kHz}$ in Figures 6(a-b)). Finally, we note that for these two cases (instability at $3.85 \mathrm{kHz}$ or $4.72 \mathrm{kHz}$ as an unique initial contributor, respectively), the unstable modes selected to initiate movement (i.e. the modal amplitudes) may disappear and therefore no longer be present in the contribution of the increasing vibration, despite the fact that they triggered the instability. This is clearly shown in Figure 5 (a,b,c,d) (in Figure 6(a,b), respectively) for which the initial unstable mode at $3.85 \mathrm{kHz}$ (at $4.72 \mathrm{kHz}$, respectively) disappears if the modal amplitudes increases. Therefore it is obvious that the initial unstable mode does not necessarily lead to the vibrational motion and may, in some cases, be only an initial contributor to instability. This also demonstrates the limitations of CEA. It can be concluded that the initial increasing unstable vibrations can be more or less complex (with the contribution of more or less unstable modes) due to the modal amplitudes of the unstable mode chosen. However, it can be noted that the number of unstable modes that emerge are limited regardless of the initial conditions imposed. We also found similarities (in terms of frequency and real parts) according to the different configurations.

Then, Figures 7, 8 and 9 show the results for the three instabilities at $3.69 \mathrm{kHz}, 4.94 \mathrm{kHz}$ and $5.34 \mathrm{kHz}$. The previous remarks are still valid for each case. The contributions of several unstable modes are present. These contributions can be more or less significant depending on the changes in the modal amplitudes of the predefined unstable mode. In every case, the unstable mode with the largest real part is always the same. This instability can be seen at $4.72 \mathrm{kHz}$ for small modal amplitudes which increase to $4.9 \mathrm{kHz}$ when augmenting the modal amplitudes of a predefined unstable mode. This interesting information (that cannot be obtained through conventional CEA analysis) informs us which unstable mode governs the initial increase in the level of vibrations.

Table 1 gives an overview of the computation times involved. As an indication, the disk space used to store the MASA results exploited in this section was around $1 \mathrm{Mb}$ for each reduced model (matlab binary format .mat was used). If more processors had been used for the MASA calculations and by performing all the calculations in parallel, it would have been possible to limit the total time to slightly longer than the Abaqus wall-clock time for RM104, at least. A compromise could also be defined between the number of contact elements in the reduced model, the number of steps for the modal amplitude sweep and the number of processors needed 
to run the MASA.

[Fig. 4 about here.]

[Fig. 5 about here.]

[Fig. 6 about here.]

[Fig. 7 about here.]

[Fig. 8 about here.]

[Fig. 9 about here.]

[Table 1 about here.]

Finally, we propose to show the evolution of contacts at the frictional interface. Therefore, for a specific friction coefficient $\mu=0.7$, Figures 10 (a), (b) and (c) give the status for each contact element according to the modal amplitude $p$ of one of the three main instabilities (at $1.98 \mathrm{kHz}$, $3.85 \mathrm{kHz}$ or $4.7 \mathrm{kHz})$. Three configurations of the contact status at the frictional interface are considered with the following visual representations: nothing in case of non-contact, a dot in case of permanent contact and a full red circle in case of impacts.

When the modal amplitude $p$ increases, we can observe the occurrence of impacts for each configuration. Moreover, the global evolutions of the impacts for the three main instabilities appear to be generally similar with regard to their locations (see Figures 10 (a), (b) and (c)). When comparing the evolution of the real part versus the modal amplitude $p$ (see Figure 4(b), 5(d) and 6(d), respectively) and the evolution of contact status (see Figure 10(a), (b) and (c), respectively), it is easy to see that the occurrences of impacts can tend towards stabilization by lowering the evolution of the real part or towards destabilization by increasing it.

In some cases, it is important to note that micro-impacts are sufficient to stabilize the modal response (when the real part reaches zero) and so the vibrational amplitude of the brake system can be approximated by using the MASA methodology and results. For example, we consider the configuration with the modal amplitude $p$ of the second unstable mode (at $3.8 \mathrm{kHz}$ ) for $\mu=0.2$. As shown previously in Figure 5(a), stationary responses are obtained for two specific modal amplitudes (for $p=100$ and $p=440$ ). As indicated in Figure 10(d), these two modal amplitudes correspond to two different contact statuses at the frictional interface. All these results illustrate the fact that the local status at the frictional interface between the pad and the disc can also play an important role in the generation of increasing self-excited vibrations. 
[Fig. 10 about here.]

\section{Conclusion}

This paper proposed a new method called Modal Amplitude Stability Analysis based on the transformation of the first harmonic approximation of equations of motion (using Harmonic Balance Method) into a state-space system compatible with a stability analysis.

This approach and the evolution of the real parts of the dynamic system versus modal amplitudes were used to detect the occurrence and generation of increasing self-excited vibrations. For the global strategy, a new linearization was proposed for nonlinear forces at the frictional interface in order to linearize each contact element independently. This linearization introduced terms in both stiffness and damping matrices and should allow reduction on relative displacements [37] for future developments based on CHBM [29] which could probably be used to reassess the mode shape and frequency according to modal amplitudes. An application for an industrial finite element automotive brake system was presented.

The numerical results obtained and the scientific approach proposed demonstrated that the Modal Amplitude Stability Analysis is very interesting for several reasons, despite the assumption on the mode shape and the frequency of the unstable modes. Firstly, there was no convergence problem since no optimization was used. Secondly, the calculation times were compatible with industrial use, as illustrated in this present work.

In future work, we will investigate the ability of MASA methodology or derived methods to produce design criteria. We hope to develop an efficient numerical tool validated by experimental tests to design automotive brake systems, which requires better understanding and predicting squeal noise phenomena more efficiently. Another important step would be to enhance the mathematical-mechanical modeling of the automotive brake system. It is very important to obtain better understanding of squeal phenomena by improving finite element models of brake squeal in order to reproduce squeal experiments.

\section{Acknowledgments}

This work was carried out as part of the PSA Peugeot Citroën Stellab program - OpenLab Vibro-Acoustic-Tribology@Lyon (VAT@Lyon).

J.J. Sinou is grateful to the Institut Universitaire de France for its support. 


\section{References}

[1] N.M. Kinkaid, O.M. O’Reilly, and P. Papadopoulos. Automotive disc brake squeal. Journal of Sound and Vibration, 267(2003) 105-166.

[2] R.A. Ibrahim. Friction-induced vibration, chatter, squeal, and chaos part 1: mechanics of contact and friction. Am Soc Mech Eng Appl Mech Rev, 47(1994) 209-226.

[3] R.A. Ibrahim. Friction-induced vibration, chatter, squeal, and chaos part 2: dynamics and modeling. Am Soc Mech Eng Appl Mech Rev, 47(1994) 227-263.

[4] H. Ouyang, W. Nack, and Y. Yuan, and F. Chen. Numerical analysis of automotive disc brake squeal: a review. International Journal of Vehicle Noise and Vibration, 1(2005) $207-231$.

[5] A.R. AbuBakar and H. Ouyang. A prediction methodology of disk brake squeal using complex eigenvalue analysis. International Journal of Vehicle Design, 46(2008) 416-435.

[6] F. Massi, Y. Berthier, and L. Baillet. Contact surface topography and system dynamics of brake squeal. Wear, 265(2008) 1784-1792.

[7] A. Akay, O. Giannini, F. Massi, and A. Sestieri. Disc brake squeal characterization through simplified test rigs. Mechanical Systems and Signal Processing, 23(2009) 2590-2607.

[8] A. Culla and F. Massi. Uncertainty model for contact instability prediction. The Journal of the Acoustical Society of America, 126(2009) 1111-1119.

[9] E. Sarrouy, O. Dessombz, and J.-J. Sinou. Piecewise polynomial chaos expansion with an application to brake squeal of linear brake system. Journal of Sound and Vibration, $332(2013) 577-594$.

[10] T. Butlin and J. Woodhouse. Friction-induced vibration: quantifying sensitivity and uncertainty. Journal of Sound and Vibration, 329(2010) 509-526.

[11] A. Nobari, H. Ouyang and P. Bannister. Uncertainty quantification of squeal instability via surrogate modelling. Mechanical Systems and Signal Processing, 60-61(2015) 887-908.

[12] A. Nobari, H. Ouyang and P. Bannister. Statistics of complex eigenvalues in friction-induced vibration. Journal of Sound and Vibration, 338(2015) 169-183. 
[13] L. Nechak, F. Gillot, S. Besset and J-J. Sinou. Sensitivity analysis and Kriging based models for robust stability analysis of brake systems. Mechanics Research Communications, 69(2015) 136-145.

[14] A. Heussaff, L. Dubar, T. Tison, M. Watremez, and R. F. Nunes. A methodology for the modelling of the variability of brake lining surfaces. Wear, 289(2012) 145-159.

[15] N. Hoffmann, and L. Gaul, Effects of damping on mode-coupling instability in friction induced oscillations. ZAMM Zeitschrift fur Angewandte Mathematik und Mechanik, $83(2003) 524-534$.

[16] B. Hervé, J-J. Sinou,H. Mahé ,L. Jézéquel. Extension of the destabilization paradox to limit cycle amplitudes for a nonlinear self-excited system subject to gyroscopic and circulatory actions. Journal of Sound and Vibration, 323(2009) 944-973.

[17] G. Fritz, J-J. Sinou, J.-M. Duffal, and L. Jézéquel, Investigation of the relationship between damping and mode coupling patterns in case of brake squeal. Journal of Sound and Vibration, 307(2007) 591-609.

[18] H. Festjens, G. Chevallier, F. Renaud, J.-L. Dion, and R. Lemaire. Effectiveness of multilayer viscoelastic insulators to prevent occurrences of brake squeal: A numerical study. Applied Acoustics, 73(2012) 1121-1128.

[19] S. Oberst, J. C. S. Lai, and S. Marburg. Guidelines for numerical vibration and acoustic analysis of disc brake squeal using simple models of brake systems. Journal of Sound and Vibration, 332(2013) 2284-2299.

[20] K. Soobbarayen, S. Besset, and J-J. Sinou. A simplified approach for the calculation of acoustic emission in the case of friction-induced noise and vibration. Mechanical Systems and Signal Processing, 50(2015) 732-756.

[21] J.-J. Sinou. Transient non-linear dynamic analysis of automotive disc brake squeal â On the need to consider both stability and non-linear analysis. Mechanics Research Communications, 37(2010) 96-105.

[22] F. Massi, L. Baillet, O. Giannini, and A. Sestieri. Brake squeal: linear and nonlinear numerical approaches. Mechanical Systems and Signal Processing, 21(2007) 2374-2393, 2007. 
[23] S. Oberst and J.C.S. Lai, Nonlinear transient and chaotic interactions in disc brake squeal. Journal of Sound and Vibration, 342(2015) 272-289.

[24] I. Iroz, M. Hanss and P. Eberhard, Transient simulation of friction-induced vibrations using an elastic multibody approach. Multibody system dynamics, (2016) 1-13.

[25] A.R. AbuBakar and H. Ouyang. Complex eigenvalue analysis and dynamic transient analysis in predicting disc brake squeal. International Journal of Vehicle Noise and Vibration, $2(2006)$ 143-155.

[26] J.-J. Sinou, A. Loyer, O. Chiello, G. Mogenier, X. Lorang, F. Cocheteux, and S. Bellaj. A global strategy based on experiments and simulations for squeal prediction on industrial railway brakes. Journal of Sound and Vibration, 332(2013) 5068-5085.

[27] S. Oberst and J.C.S. Lai. Statistical analysis of brake squeal noise. Journal of Sound and Vibration, 330(2011) 2978-2994.

[28] S. Oberst and J.C.S. Lai. Chaos in brake squeal noise. Journal of Sound and Vibration, $330(2011) 955-975$.

[29] N. Coudeyras, S. Nacivet, and J.-J. Sinou. Periodic and quasi-periodic solutions for multiinstabilities involved in brake squeal. Journal of Sound and Vibration, 328(2009) 520-540.

[30] O.N. Kirillov. Destabilization paradox due to breaking the Hamiltonian and reversible symmetry. International Journal of Non-linear Mechanics, 42(2007) 71-87.

[31] P. Hagedorn, M. Eckstei, E. Heffel and A. Wagner. Self-Excited Vibrations and Damping in Circulatory Systems. Journal of Applied Mechanics, 81(2014) 101009:1-9.

[32] O.M. O'Reilly, N.K. Malhotra, and N.S. Namachchivaya. Some aspects of destabilization inreversible dynamical systems with application to follower forces. Nonlinear Dynamics, 10(1996) 63-87.

[33] O.N. Kirillov and A.P. Seyranian. Stabilization and destabilization of a circulatory system by small velocity-dependent forces. Journal of Sound and Vibration, 283(2004)781-800.

[34] G. Herrmann. Dynamics and stability of mechanical systems with follower forces. National Aeronautics and Space Administration, Washington D.C., 1971. 
[35] G. Herrmann, and I.C. Jong. On the destabilizing effect of damping in nonconservative elastic systems. Journal of Applied Mechanics, 32(1965) 592-597.

[36] O. Fazio, S. Nacivet, and J.-J. Sinou. Reduction strategy for a brake system with local frictional nonlinearities - Application for the prediction of unstable vibration modes. Journal of Applied Acoustics, 91(2015) 12-24.

[37] S. Nacivet, C. Pierre, F. Thouverez, and L. Jezequel. A dynamic lagrangian frequency time method for the vibration of dry friction damped systems. Journal of Sound and Vibration, $265(2003)$ 201-219. 


\section{List of Figures}

$1 \quad$ Brake system details $\ldots \ldots \ldots \ldots \ldots \ldots \ldots$

$2 \quad$ Superelement validation according to sensitivity analysis . . . . . . . . . . . . . 21

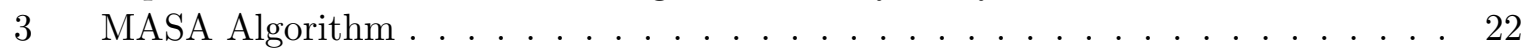

$4 \quad$ Residual real parts according to modal amplitude . . . . . . . . . . . . . . . . . 23

5 Residual real parts according to modal amplitude . . . . . . . . . . . . . . . . 24

$6 \quad$ Residual real parts according to modal amplitude . . . . . . . . . . . . . . 25

7 Residual real parts according to modal amplitude . . . . . . . . . . . . . . 26

$8 \quad 5000$ - Residual real parts according to modal amplitude . . . . . . . . . . . . 27

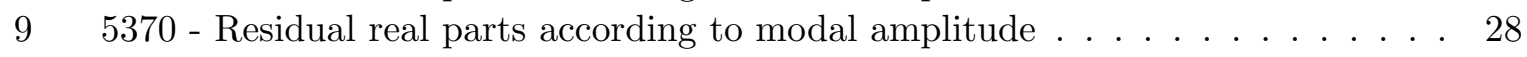

$10 \quad$ Impacts postprocessing . . . . . . . . . . . . . . . . . . . . 29 


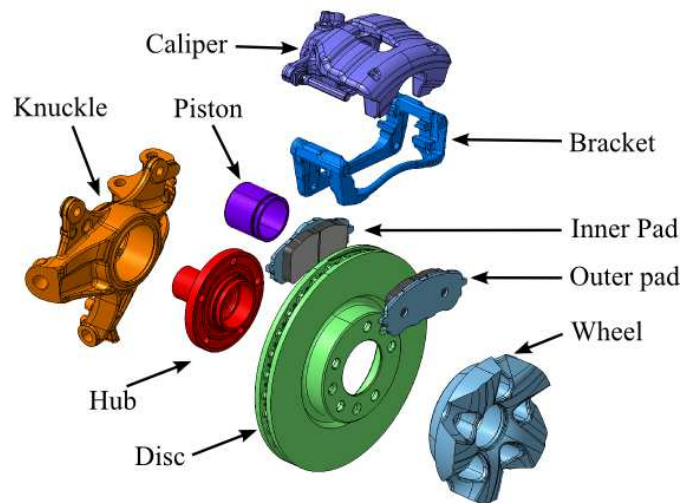

(a) Exploded view

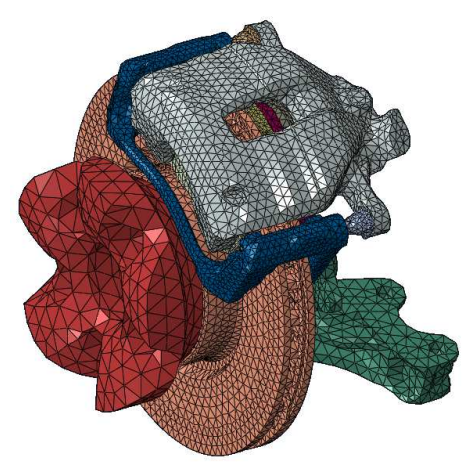

(b) Finite element model

Fig. 1. Brake system details 


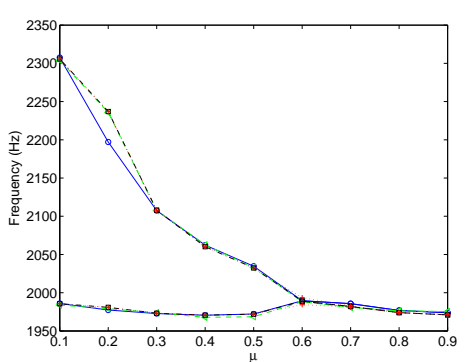

(a) Frequencies at $1.98 \mathrm{kHz}$

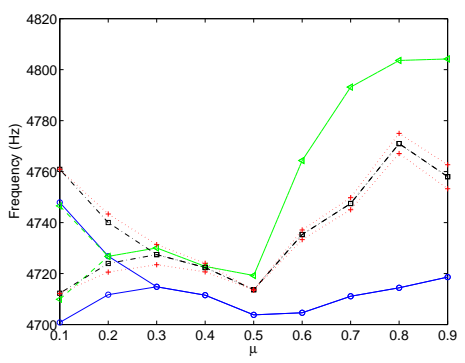

(d) Frequencies at $4.72 \mathrm{kHz}$

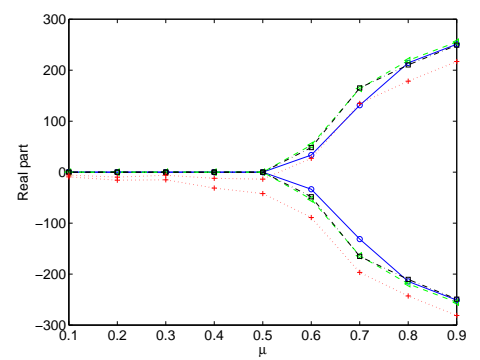

(g) Real parts at $1.98 \mathrm{kHz}$

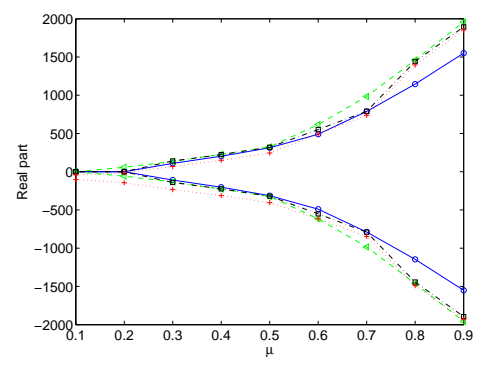

(j) Real parts at $4.72 \mathrm{kHz}$

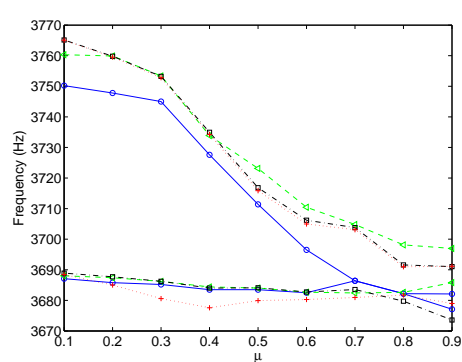

(b) Frequencies at $3.69 \mathrm{kHz}$

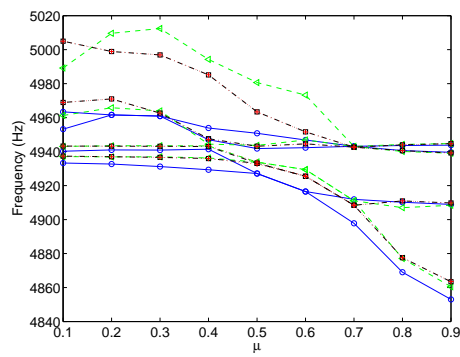

(e) Frequencies at $4.94 \mathrm{kHz}$

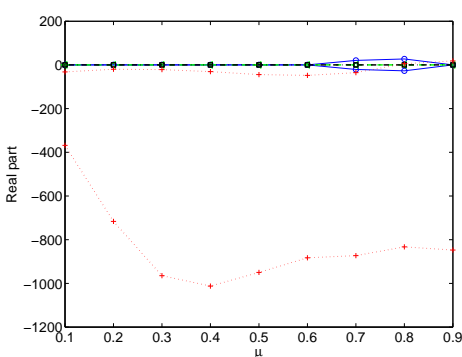

(h) Real parts at $3.69 \mathrm{kHz}$

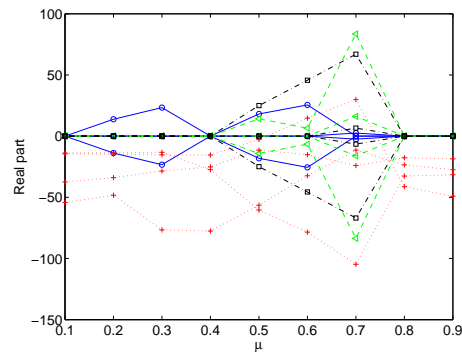

(k) Real parts at $4.94 \mathrm{kHz}$

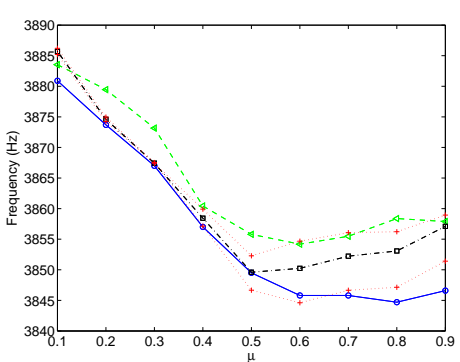

(c) Frequencies at $3.85 \mathrm{kHz}$

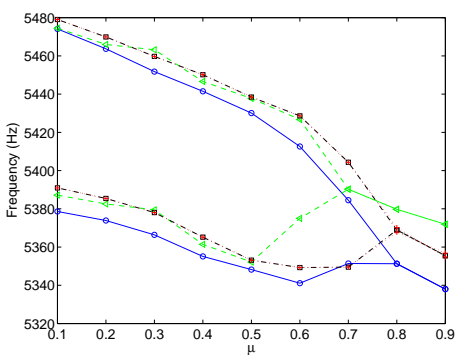

(f) Frequencies at $5.34 \mathrm{kHz}$

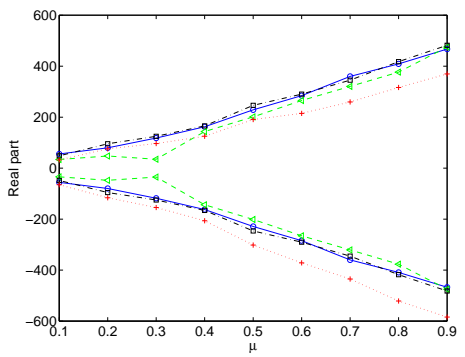

(i) Real parts at $3.85 \mathrm{kHz}$

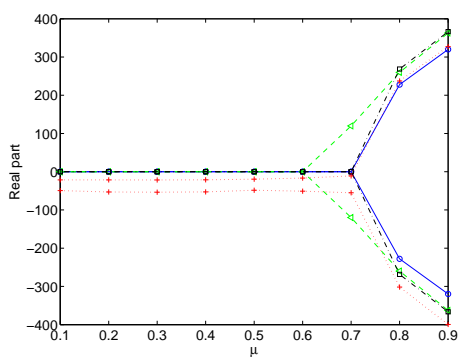

(l) Real parts at $5.34 \mathrm{kHz}$

Fig. 2. Evolution of eigenvalues, frequencies and real parts according to the friction coefficient $\mu$ for all instabilities. A new superelement is generated at each $\mu$ for the complex eigenvalue analysis on reduced models. A damping coefficient of $\xi=1 e-6$ is applied for RM212-damped. 


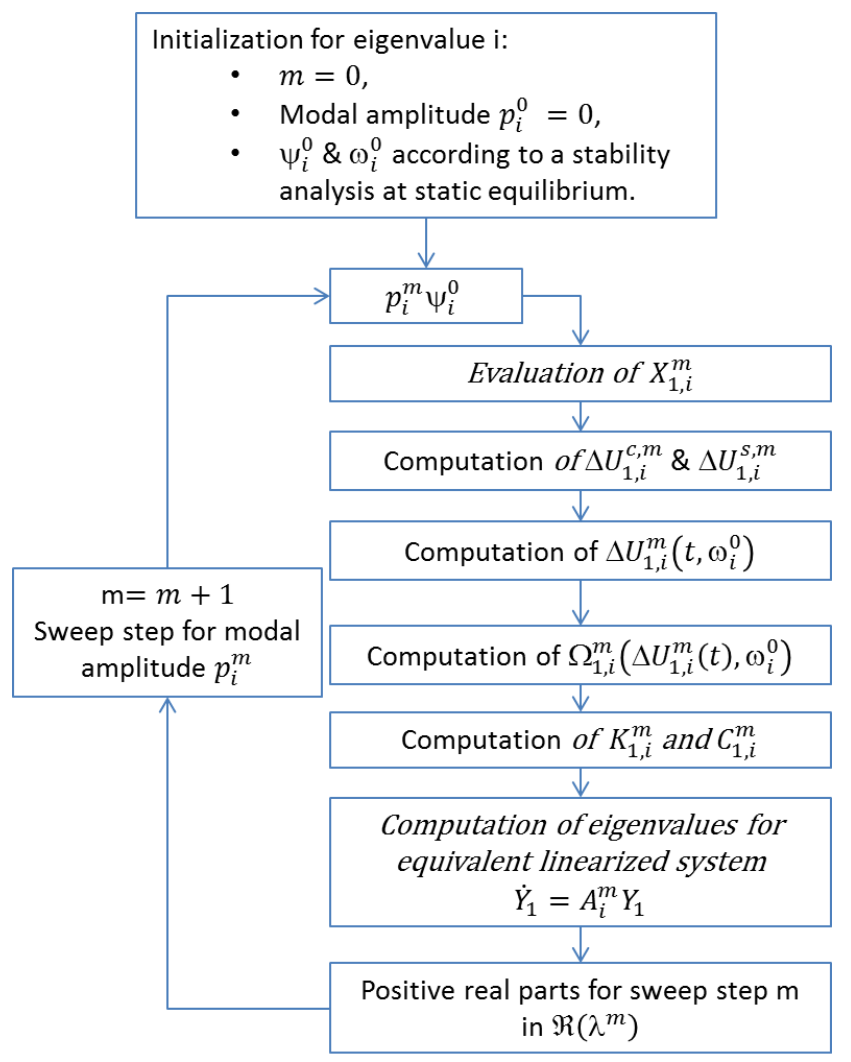

Fig. 3. Algorithm of the Modal Amplitude Stability Analysis method. 


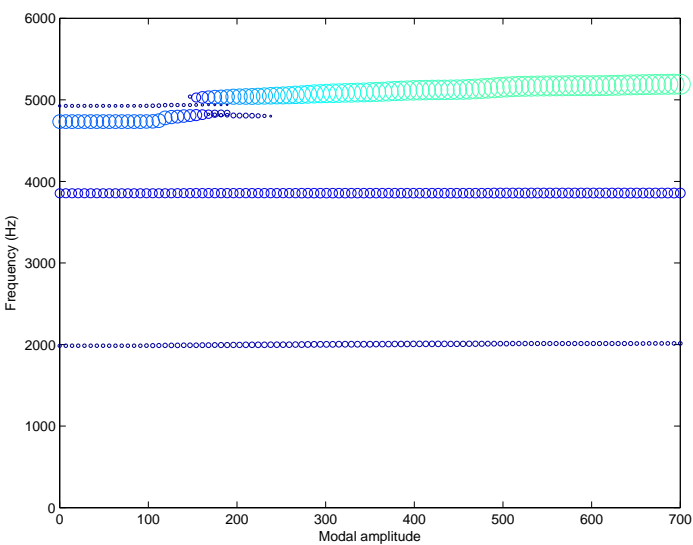

(a) $\mu=0.6$

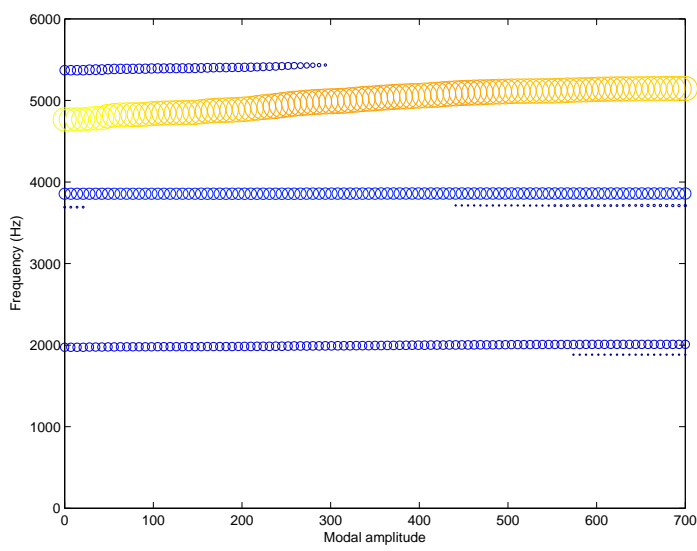

(c) $\mu=0.8$

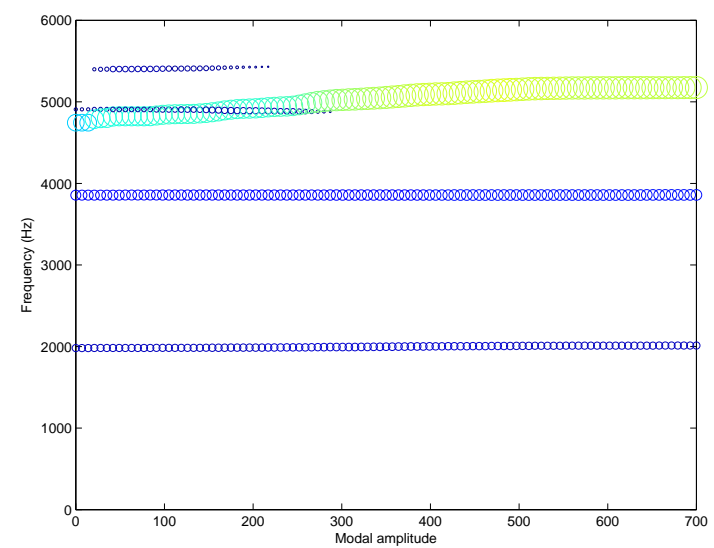

(b) $\mu=0.7$

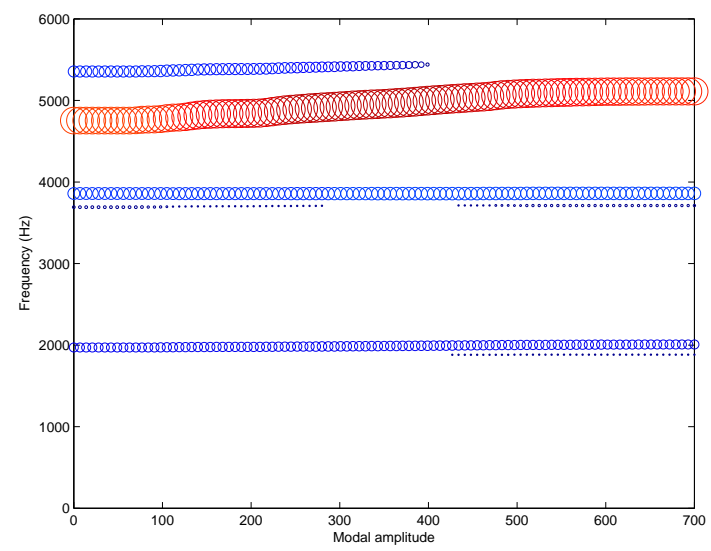

(d) $\mu=0.9$

Fig. 4. Evolution of real parts according to modal amplitude for the instability at $1.98 \mathrm{kHz}$ - the colorbar is associated with the real part of the eigenvalues 


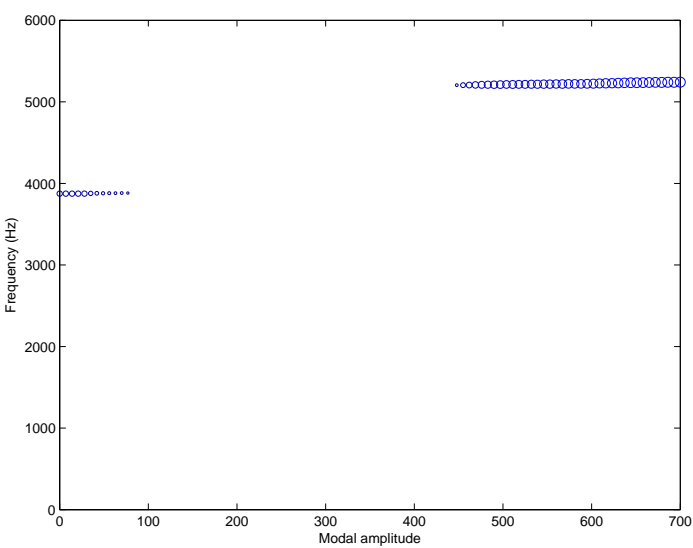

(a) $\mu=0.2$

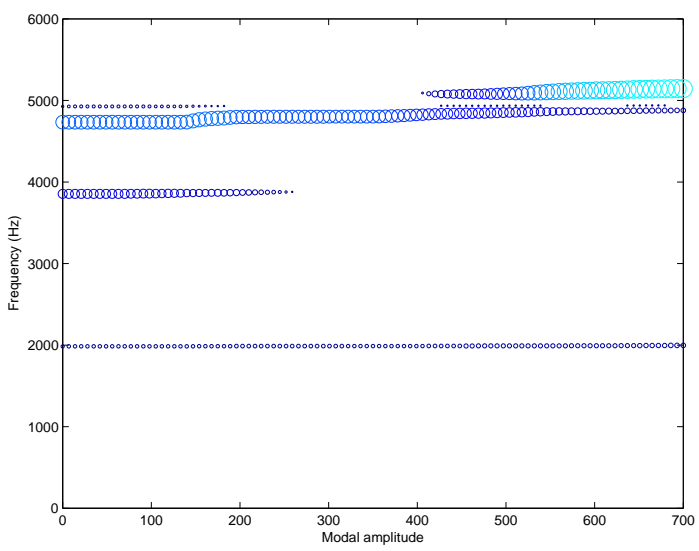

(c) $\mu=0.6$

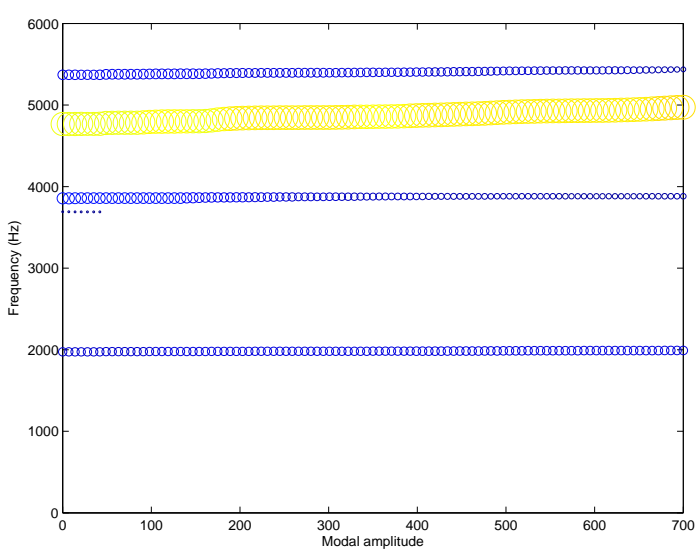

(e) $\mu=0.8$

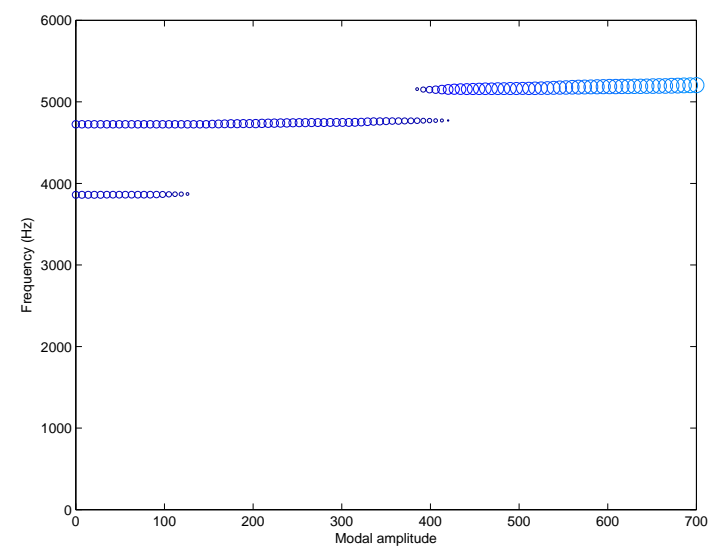

(b) $\mu=0.4$

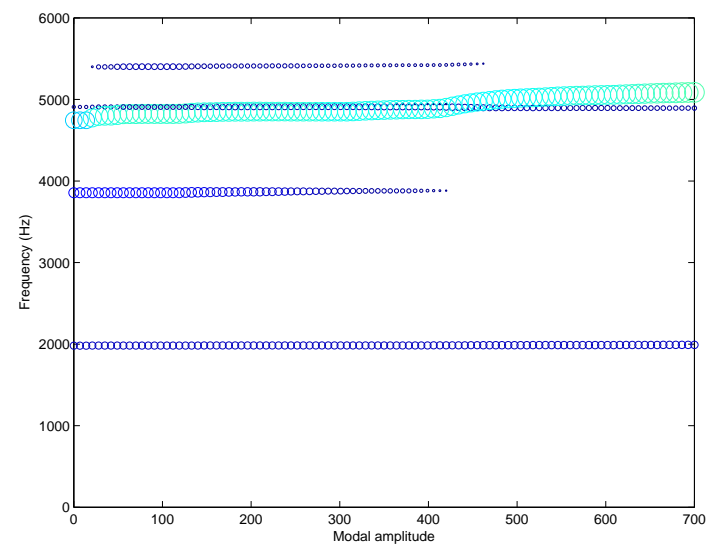

(d) $\mu=0.7$

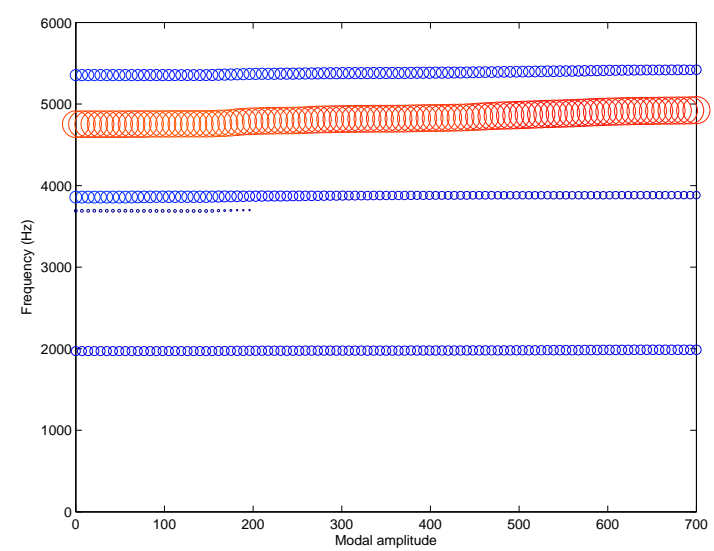

(f) $\mu=0.9$

Fig. 5. Evolution of real parts according to modal amplitude for the instability at $3.85 \mathrm{kHz}-$ the colorbar is associated with the real part of the eigenvalues 


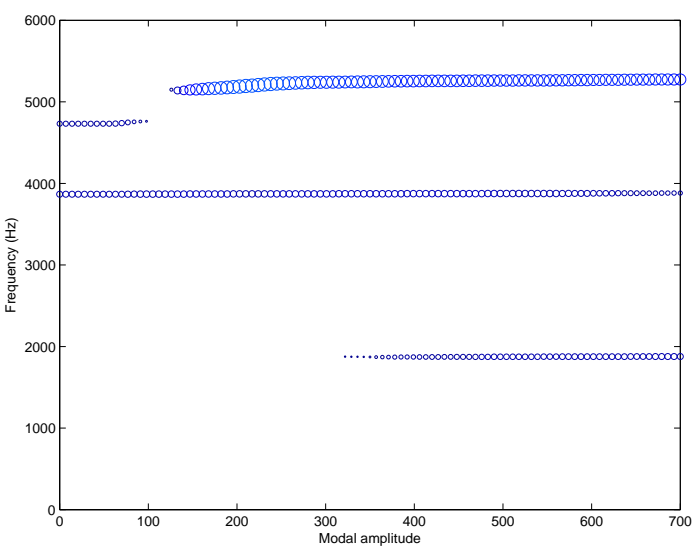

(a) $\mu=0.3$

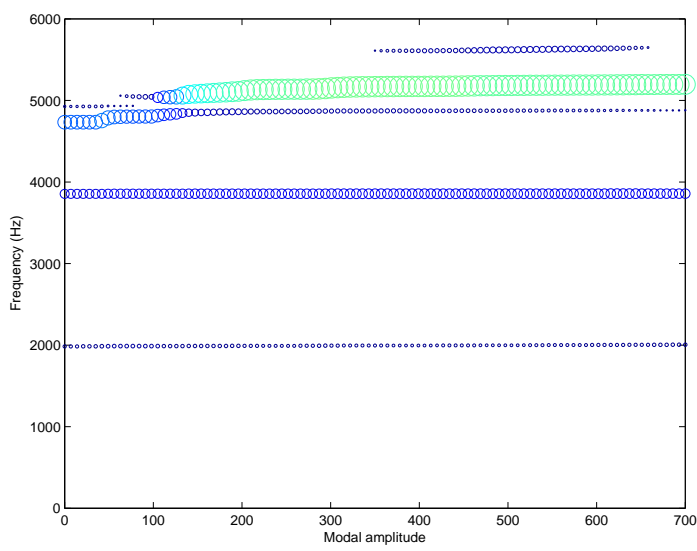

(c) $\mu=0.6$

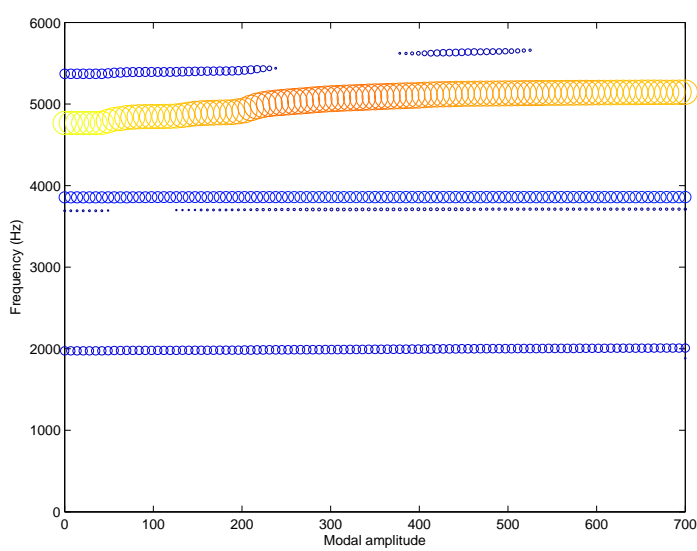

(e) $\mu=0.8$

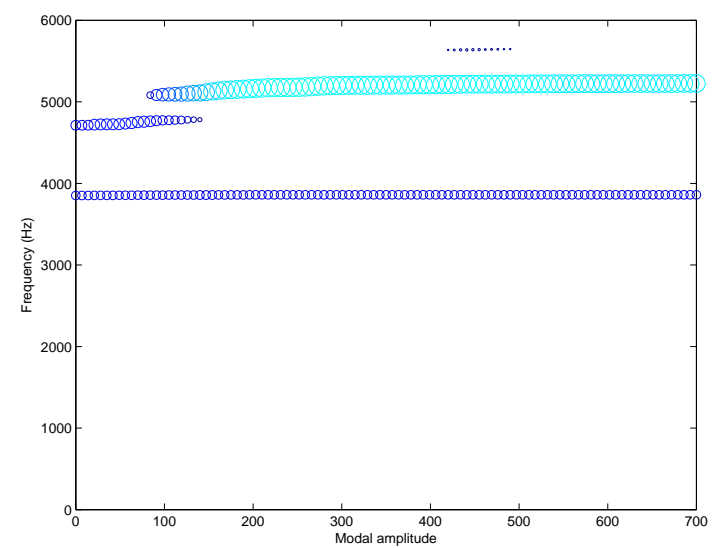

(b) $\mu=0.5$

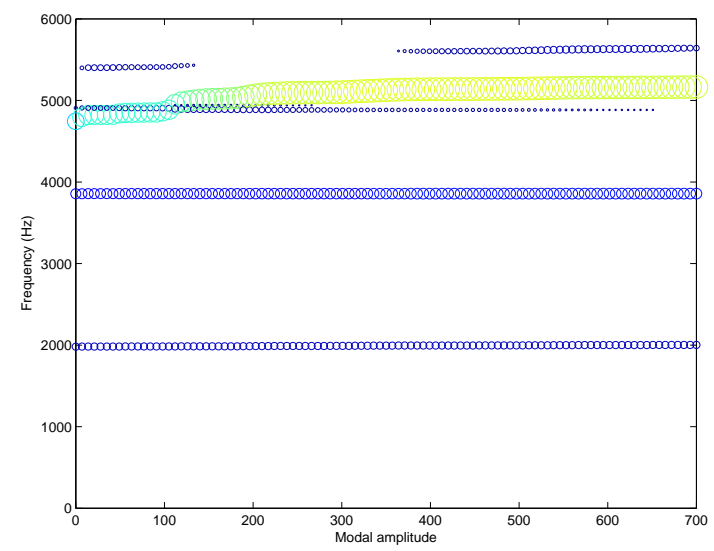

(d) $\mu=0.7$

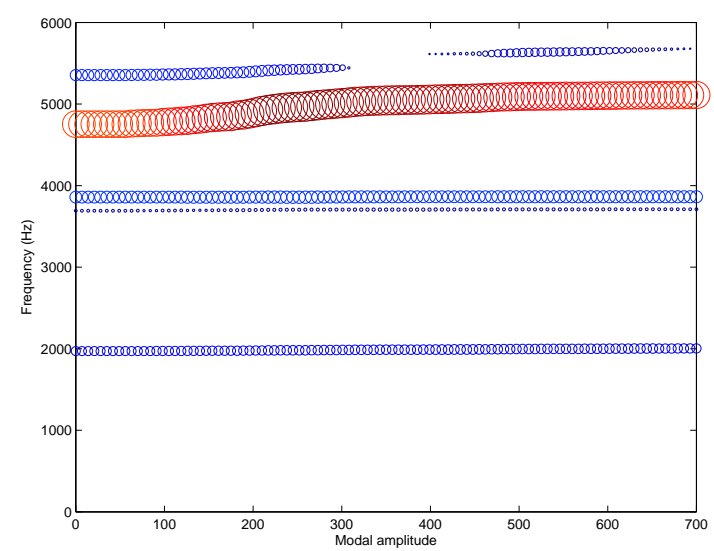

(f) $\mu=0.9$

Fig. 6. Evolution of real parts according to modal amplitude for the instability at $4.72 \mathrm{kHz}$ - the colorbar is associated with the real part of the eigenvalues 


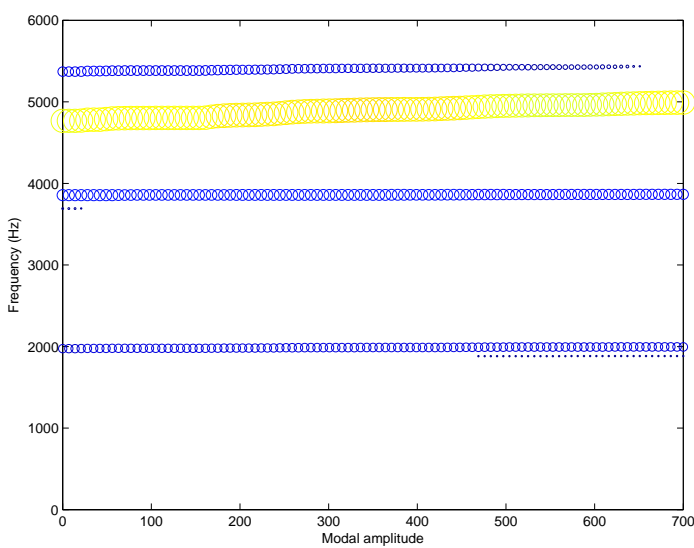

(a) $\mu=0.8$

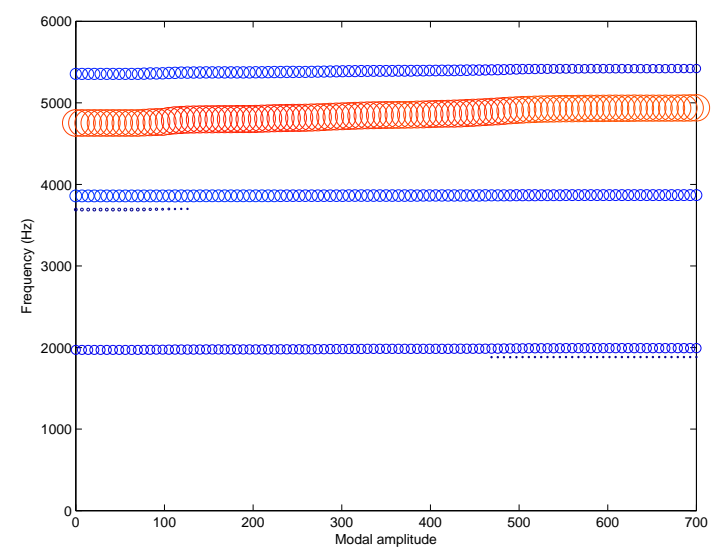

(b) $\mu=0.9$

Fig. 7. Evolution of real parts according to modal amplitude for the instability at $3.69 \mathrm{kHz}-$ the colorbar is associated with the real part of the eigenvalues 


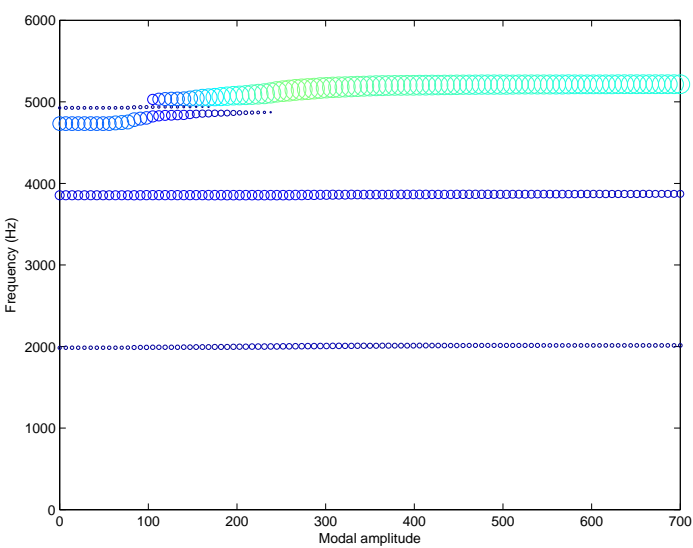

(a) $\mu=0.6$

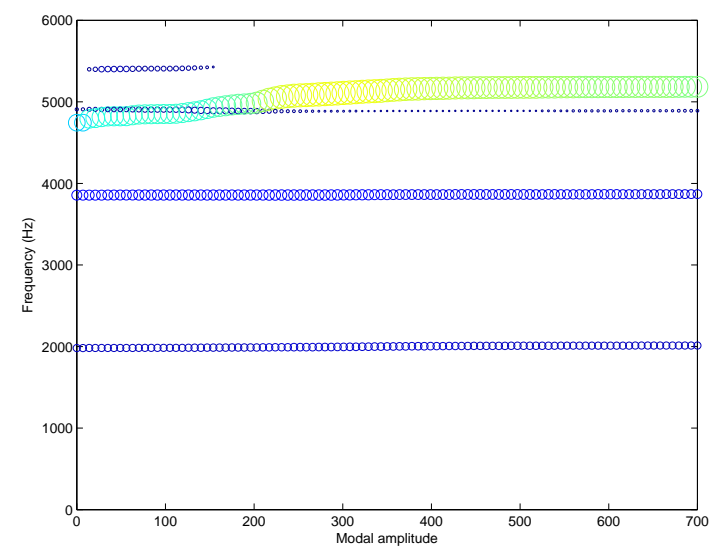

(b) $\mu=0.7$

Fig. 8. Evolution of real parts according to modal amplitude for the instability at $4.94 \mathrm{kHz}$ - the colorbar is associated with the real part of the eigenvalues 


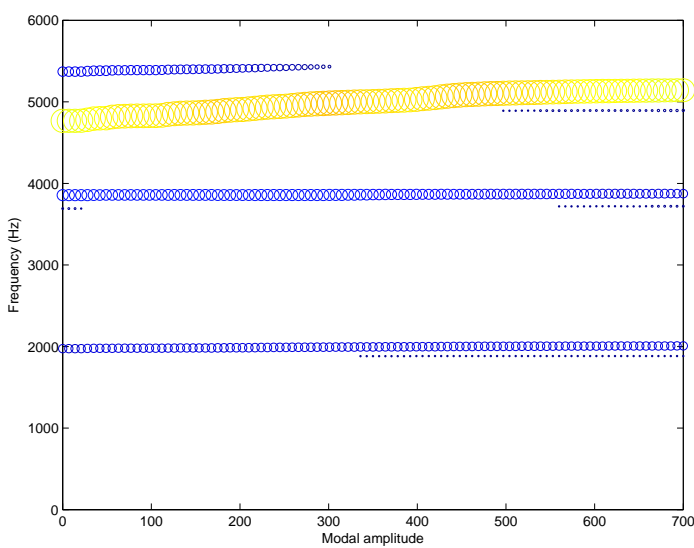

(a) $\mu=0.8$

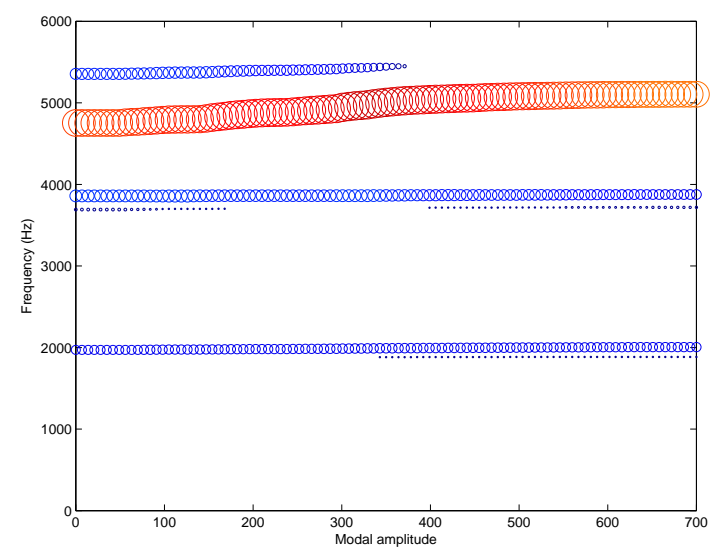

(b) $\mu=0.9$

Fig. 9. Evolution of real parts according to modal amplitude for the instability at $5.34 \mathrm{kHz}$ - the colorbar is associated with the real part of the eigenvalues 


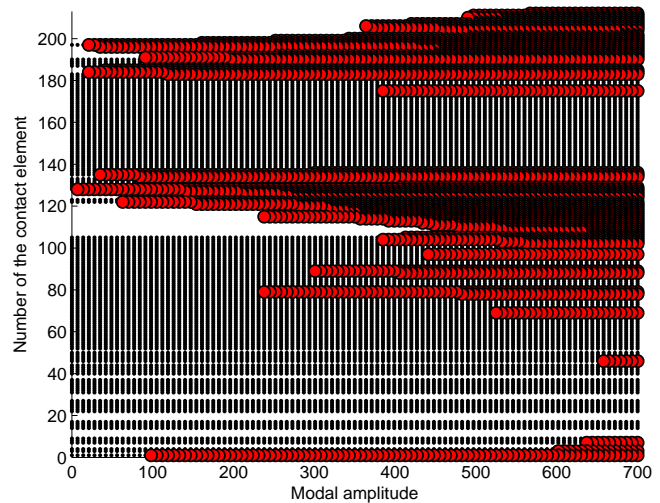

(a) $1.98 \mathrm{kHz}$ at $\mu=0.7$

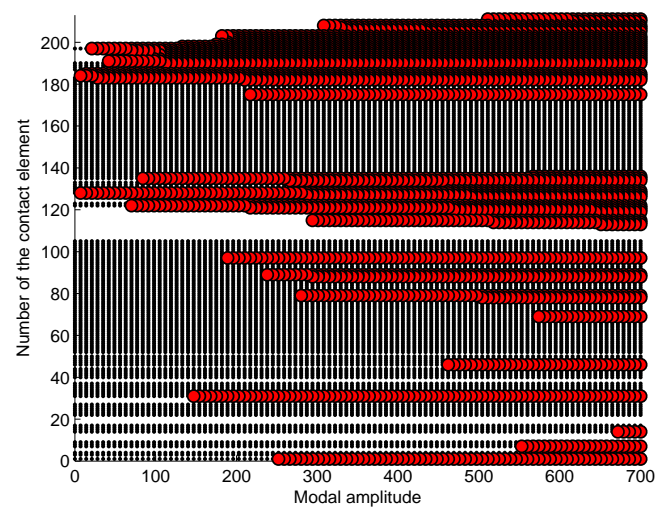

(c) $4.7 \mathrm{kHz}$ at $\mu=0.7$

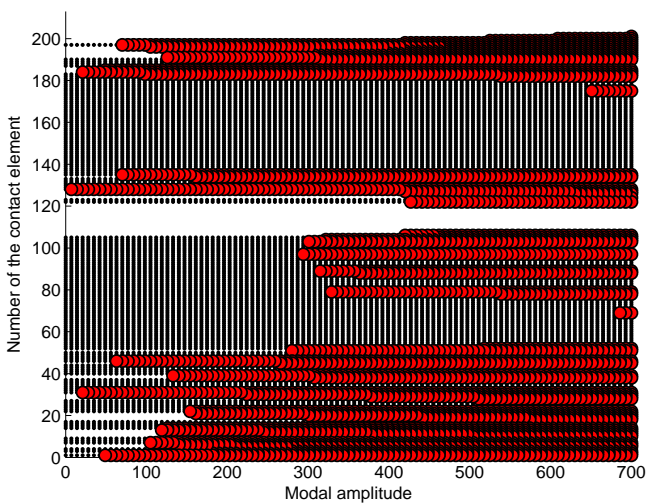

(b) $3.8 \mathrm{kHz}$ at $\mu=0.7$

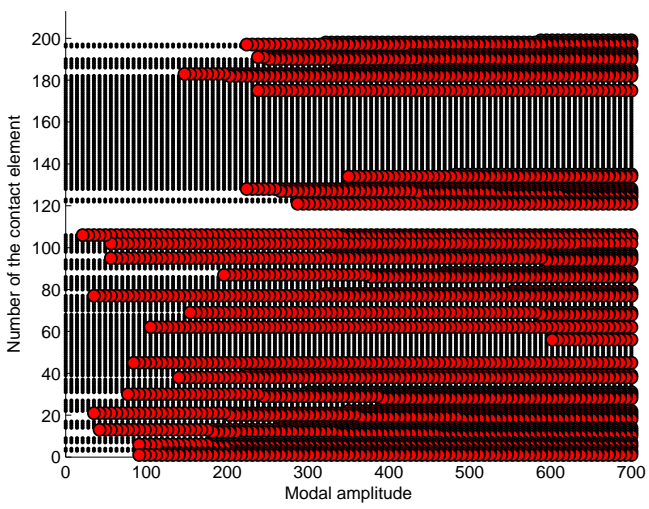

(d) $3.8 \mathrm{kHz}$ at $\mu=0.2$

Fig. 10. Postprocessing of impacts according to modal amplitude for the three main instabilities 


\section{List of Tables}

$1 \quad$ Overview of computation times $\ldots \ldots \ldots \ldots \ldots \ldots \ldots \ldots$ 


\begin{tabular}{|l|r|r|}
\hline & RM104 & RM212 \\
\hline Number of superelements to generate by Abaqus & 9 & 9 \\
Number of instabilities to evaluate by MASA & 30 & 28 \\
\hline Total time to generate superelements & $1 h 52^{\prime}$ & $1 h 52^{\prime}$ \\
Total time for MASA evaluations (100 steps on the 0 - 700 sweep) & $5 h 24^{\prime}$ & $29 h 07^{\prime}$ \\
Total time for MASA evaluations with sweep break & $3 h 06^{\prime}$ & $18 h 22^{\prime}$ \\
\hline
\end{tabular}

Table 1. Overview of computation times for both reduced models depending on the use or not of the sweep break condition $\Re\left(\lambda_{i}^{m}\right)$. The calculations were performed using PSA Peugeot Citroën servers for Abaqus and a desktop computer equipped with an Intel(R) Xeon(R) CPU E5-1620 v2 @3.7GHz processor for the MASA solver. The MASA solver was compiled with Matlab R2013a 64b. 